\title{
Effect of physical pretreatment on dilute acid hydrolysis of water hyacinth (Eichhornia crassipes).
}

\begin{abstract}
Effects of different physical pretreatments on water hyacinth for dilute acid hydrolysis process $\left(121 \pm 3{ }^{\circ} \mathrm{C}, 5 \% \mathrm{H} 2 \mathrm{SO} 4,60 \mathrm{~min}\right)$ were comparatively investigated. Untreated sample had produced $24.69 \mathrm{mg}$ sugar/g dry matter. Steaming $\left(121 \pm 3{ }^{\circ} \mathrm{C}\right)$ and boiling $\left(100 \pm 3{ }^{\circ} \mathrm{C}\right)$ for $30 \mathrm{~min}$ had provided $35.9 \%$ and $52.4 \%$ higher sugar yield than untreated sample, respectively. The highest sugar yield $(132.96 \mathrm{mg}$ sugar/g dry matter) in ultrasonication was obtained at $20 \mathrm{~min}$ irradiation using $100 \%$ power. The highest sugar production $(155.13 \mathrm{mg}$ sugar/g dry matter) was obtained from pulverized samples. Hydrolysis time was reduced when using samples pretreated by drying, mechanical comminution and ultrasonication. In most methods, prolonging the pretreatment period was ineffective and led to sugar degradations. Morphology inspection and thermal analysis had provided evidences of structure disruption that led to higher sugar recovery in hydrolysis process.
\end{abstract}

Keyword: Physical pretreatment; Water hyacinth; Dilute acid hydrolysis; Morphology. 